\title{
Hidradenitis Suppurativa: An Asian Perspective from a Singaporean Institute
}

\author{
Ellie Choi ${ }^{a}$ Alex R. Cook ${ }^{b}$ Nisha Suyien Chandran ${ }^{a}$

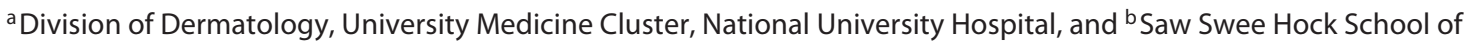 \\ Public Health, National University of Singapore and National University Health System, Singapore
}

\section{Keywords}

Hidradenitis suppurativa $\cdot$ Acne inversa $\cdot$ Asian population .

Demographics

\begin{abstract}
Background: Demographic studies of hidradenitis suppurativa (HS) in Western countries have found an association with the female gender and with co-morbidities, such as the metabolic syndrome. There are few studies in an Asian context. Objective: This study examines the characteristics of HS at a Singaporean institute and compares them to those of existing studies in the West. Methods: We report a series of 58 patients with HS seen at the University Dermatological Clinic, National University Hospital, Singapore, over a 13year period between January 2004 and December 2016. Results: Of 58 patients, 34 were male ( $58.6 \%)$. The axilla was the most common site affected, followed by the groin and buttocks. We did not find significant differences in disease characteristics between males and females, such as disease severity or location of disease. Metabolic co-morbidities were common, although paediatric-onset HS patients were less likely to be overweight, obese or smokers. Conclusion: The higher proportion of male HS patients in our cohort compared to the West may reflect differences in the prevalence
\end{abstract}

of obesity and smoking in the 2 populations. Metabolic comorbidities were similarly prevalent in both adult and paediatric HS patients. These findings offer insight into the factors influencing the development of HS.

C 2018 S. Karger AG, Basel

\section{Introduction}

Hidradenitis suppurativa (HS) is a recurrent and debilitating skin disease of the hair follicle that usually presents after puberty, with painful, deep-seated, inflamed lesions in the apocrine gland-bearing areas of the body, most commonly the axillae and inguinal and anogenital regions [1].

Reports on HS have increasingly often appeared in the literature in the past 10 years, with case series and population-based studies in Europe and America highlighting it as an important systemic disease with multiple associated co-morbidities [2-5]. These studies have reported a prevalence ranging from 0.078 to $4 \%$ [4-6] at a female:male ratio of approximately $3: 1$ [4-7]. The cause for the female predominance is uncertain, but postulated reasons include differences in self-care (such as shaving of hair-bearing sites), in hormones or in health-seeking behaviour [8].

\section{KARGER}

(c) 2018 S. Karger AG, Basel

E-Mail karger@karger.com

www.karger.com/sad
Dr. Nisha Suyien Chandran

Division of Dermatology, University Medicine Cluster National University Hospital, 1E Kent Ridge Road

NUHS Tower Block, Level 10, Singapore 119228 (Singapore)

E-Mail nisha_suyien_chandran@ @uhs.edu.sg 
Several risk factors have been identified: there is a positive association between metabolic syndrome and HS [2-5], while obesity and smoking are common among HS patients, with the mean body mass index (BMI) in HS patients ranging from 25.6 to 32.6 and the majority of patients being smokers or ex-smokers [5].

Most studies on HS have been carried out in the United States and Europe. HS is thought to be rare among Asians, and a review of the literature on PubMed with the keywords "hidradenitis suppurativa" and "demographics" found only 2 relevant studies reporting the demographics of HS in an Asian population. The first is a study of Japanese patients with HS [9] and the second a Chinese study of familial HS [10].

This study examines the characteristic of HS and its co-morbidities in a tertiary institute in the South-East Asian city-state of Singapore, whose population is predominantly composed of ethnic Chinese (74.1\%), Malays (13.4\%) and Indians (9.2\%) [11].

\section{Materials and Methods}

We reviewed the diagnoses of all new patients seen at the University Dermatology Clinic of the National University Hospital in Singapore between January 1, 2004, and December 31, 2016. Patients who had an initial diagnosis of HS, acne inversa, recurrent folliculitis or recurrent furunculosis were identified and their charts reviewed by the first author. Those with a final diagnosis consistent with HS were included.

Patients' demographic profile, co-morbidities and clinical findings were extracted from medical chart records. Patients were considered as smokers if they had been smoking daily within the last 6 months. Dyslipidaemia was defined as having a high level of any of the following: triglycerides $>2.3 \mathrm{mmol} / \mathrm{L}$, low-density lipoprotein $>3.3 \mathrm{mmol} / \mathrm{L}$, total cholesterol $>5.2 \mathrm{mmol} / \mathrm{L}$; or a low level of high-density lipoprotein $<1 \mathrm{mmol} / \mathrm{L}$, based on Singapore's clinical practice guidelines [12].

The severity of disease was graded by the Hurley classification [1] into stages I, II and III. Progress and response to treatment were recorded. Where there was uncertainty in the documentation of severity or response, the senior author was consulted.

Data were analysed using SPSS version 21 and $\mathrm{R}$ version 3.3.1 [13]. This study was approved by the hospital research ethics committee.

\section{Results}

Fifty-eight patients were identified, of whom 34 (59\%) were males. Patient demographics and co-morbidities are shown in Table 1 . The median age of symptom onset was 20 years (interquartile range: 16-28). The youngest age at
Table 1. Patient characteristics

\begin{tabular}{|c|c|c|}
\hline & $n$ & $\%$ \\
\hline \multicolumn{3}{|l|}{ Gender } \\
\hline Male & 34 & 58.6 \\
\hline Female & 24 & 41.4 \\
\hline \multicolumn{3}{|c|}{ Age of symptom onset } \\
\hline$\leq 19$ years & 28 & 48.3 \\
\hline $20-29$ years & 20 & 34.5 \\
\hline $30-39$ years & 6 & 10.3 \\
\hline$\geq 40$ years & 4 & 6.90 \\
\hline \multicolumn{3}{|l|}{ Race } \\
\hline Chinese & 24 & 41.4 \\
\hline Malay & 7 & 12.1 \\
\hline Indian & 17 & 29.3 \\
\hline Others & 10 & 17.2 \\
\hline \multicolumn{3}{|c|}{ Hurley stage at presentation } \\
\hline I & 22 & 37.9 \\
\hline II & 30 & 57.1 \\
\hline III & 6 & 10.3 \\
\hline \multicolumn{3}{|c|}{ Worst Hurley stage during follow-up } \\
\hline I & 18 & 31.0 \\
\hline II & 33 & 56.9 \\
\hline III & 7 & 12.1 \\
\hline \multicolumn{3}{|c|}{ Disease involvement at presentation } \\
\hline Axilla & 49 & 84.5 \\
\hline Groin & 25 & 43.1 \\
\hline Buttock & 23 & 39.7 \\
\hline
\end{tabular}

symptom onset was 11 years, and the oldest 47 years. The median age of presentation was 23 years (interquartile range: 19-31). Ethnic Chinese were under-represented and ethnic Indians over-represented relative to the population as a whole ( $\chi^{2}$ test: $\left.p<0.0001\right)$. The axilla was the most common site involved at presentation (85\%), followed by the groin (43\%) and buttocks (40\%). Metabolic co-morbidities, such as dyslipidaemia and diabetes, as well as smoking and obesity were common amongst patients tested and more prevalent than in the general population despite the younger age profile of our patients (Table 2). Other medical conditions in our patients included polycystic ovarian disease in 3 patients and Crohn disease, follicular occlusion triad and acromegaly in $1 \mathrm{pa}-$ tient each. A positive family history was elicited in only 3 patients, 1 male and 2 females. One female had a young age of symptom onset at 11 years, while the other 2 patients had symptom onset at 16 and 19 years of age.

When compared to the ratio of 73:27 for females:males in a large study of 1,776 HS patients in the US [5], there were significantly more males in our study (binomial test: $p<0.001)$. Disease characteristics, such as location of le- 
Table 2. BMI and co-morbidities

\begin{tabular}{|c|c|c|c|c|}
\hline & $n$ (total) & $\%$ & Population, $\%^{\mathrm{a}}$ & $p$ value \\
\hline \multicolumn{5}{|l|}{ BMI } \\
\hline Normal and underweight $(<25)$ & $10(38)$ & 26.3 & 59.9 & \multirow[t]{3}{*}{$<0.0001^{*}$} \\
\hline Overweight (25-30) & $9(38)$ & 23.7 & 29.3 & \\
\hline Obese $(>30)$ & $19(38)$ & 50.0 & 10.8 & \\
\hline \multicolumn{5}{|l|}{ Metabolic co-morbidities } \\
\hline Diabetes mellitus & $10(39)$ & 17.2 & 11.3 & $0.010^{\ddagger}$ \\
\hline Hypertension & $8(48)$ & 13.8 & 23.5 & $0.31^{\ddagger}$ \\
\hline Raised LDL (>3.3 mmol/L) & $14(28)$ & 50.0 & 45.4 & $0.71^{\ddagger}$ \\
\hline Smoking & $19(35)$ & 32.8 & 14.3 & $<0.0001^{\ddagger}$ \\
\hline
\end{tabular}

Table 3. Metabolic co-morbidities and lifestyle habits stratified by age of symptom onset

\begin{tabular}{|c|c|c|c|c|c|}
\hline & \multicolumn{2}{|c|}{ Paediatric onset } & \multicolumn{2}{|l|}{ Adult onset } & \multirow[t]{2}{*}{$p$ value } \\
\hline & $\begin{array}{l}n \text { (total } \\
\text { available data) }\end{array}$ & $\%$ & $\begin{array}{l}n \text { (total } \\
\text { available data) }\end{array}$ & $\%$ & \\
\hline Total number & 18 & & 40 & & \\
\hline Diabetes mellitus & $3(12)$ & 25.0 & $7(27)$ & 25.9 & 1.00 \\
\hline Hypertension & $1(16)$ & 6.3 & $7(32)$ & 21.9 & 0.34 \\
\hline Dyslipidaemia & $5(8)$ & 62.5 & $16(20)$ & 80.0 & 0.63 \\
\hline Smoking & $2(12)$ & 16.7 & $17(23)$ & 73.9 & 0.0041 \\
\hline Overweight $(\mathrm{BMI} \geq 25)$ & $5(11)$ & 45.5 & $23(27)$ & 85.2 & 0.034 \\
\hline Obesity (BMI $\geq 30)$ & $3(11)$ & 27.3 & $16(27)$ & 59.3 & 0.15 \\
\hline
\end{tabular}

Paediatric onset is defined by being aged $\leq 16$ years at onset of hidradenitis suppurativa symptoms; adult onset means being aged $>16$ years. BMI, body mass index.

sions, BMI and disease severity, were similar between males and females. There was no association between BMI and disease severity (Spearman correlation coefficient: $0.129, p=0.440$ ). The association was similarly non-significant for diabetes and disease severity (Fisher exact test: $p=0.28$ ).

Eighteen patients (31\%) had onset of HS symptoms at 16 years of age or younger, and 48 patients $(83 \%)$ had onset of symptoms before 30 years. A comparison of comorbidities between patients with paediatric- and adultonset HS is presented in Table 3. Adult-onset HS patients were more likely to be smokers and overweight ( $\chi^{2}$ test: $p$ $=0.0041$ and 0.034 , respectively) compared to paediatriconset HS patients. There were no significant differences in disease location, severity and metabolic co-morbidities among patients with paediatric- and adult-onset.

Hidradenitis Suppurativa: An Asian Perspective

\section{Discussion}

Some findings of this study are consistent with those of the West, including a relatively young age of presentation $[3,14]$, the predominance of axillary lesions and the presence of risk factors, including smoking, dyslipidaemia, diabetes and obesity [3]. The higher frequency of groin and buttock involvement, as well as a greater severity, noted in males compared to females in previous studies was not apparent in this study.

Our study highlights possible differences between paediatric- and adult-onset HS. Adult-onset HS patients were significantly more likely to be overweight or smokers. HS in these older patients could develop as a secondary phenomenon due to increased friction from body folds leading to follicular occlusion. Conversely, the de- 
velopment of HS despite a normal BMI and the lack of a smoking history in the paediatric-onset patients may indicate that HS in this group is a primary phenotype which is more genetically driven. Another hypothesis is that HS as an inflammatory condition promotes the development of metabolic co-morbidities with time. Our crosssectional design precludes the differentiation of these hypotheses. Longitudinal follow-up will help determine the true frequency of metabolic co-morbidities which develop especially in the paediatric-onset group.

The detection of metabolic co-morbidities, nonetheless, is important in the paediatric-onset HS group as early intervention can reduce sequelae later in life. It is our experience that the routine testing for dyslipidaemia, hypertension and diabetes mellitus in young HS patients has led to patients being newly diagnosed and treated for these co-morbidities. It would be interesting to follow these patients closely to determine if HS severity was attenuated with early intervention for these metabolic comorbidities and conditions.

Interestingly, this study found a substantially higher male representation compared to existing studies in the West that report a female preponderance. This gender predilection was noted in both the adult and paediatric population and in all race groups, except for Indians. A male predominance was also noted in a Japanese study [9] where 69 of 100 patients recruited by questionnaire surveillance were males. This could suggest that while HS is more common in females in Western populations, the reverse may be true in East Asians.

A possible reason for the male predominance in our study may be the gender difference in obesity and smoking prevalence. In Singapore, males tend to be more obese compared to females (12.1\% obese males compared to $9.5 \%$ obese females), while in the US the converse is true $(33.4 \%$ obese males compared to $36.1 \%$ obese females) $[15,16]$. Smoking rates are also higher in men than women in Singapore (20.3 vs. $3.9 \%$ ), while in the US this difference is less pronounced (20.9 of males vs. $16.5 \%$ of females) [17]. The higher rates of HS among males in Singapore may, therefore, simply reflect a greater prevalence of risk factors, but the small sample size does not permit us to test this hypothesis. As a result, further investigation into gender and ethnic differences in apocrine gland-bearing skin may be worthwhile.

Limitations of this study include a referral bias and the small sample size, which is attributed to HS being a relatively uncommon disease. This is a single-centred study and while giving insight into HS in a multicultural popu- lation may not be generalizable to either Singapore or Asia as a whole. The retrospective nature with a relatively long period of data collection may result in missing and variable data points. As recent studies have reported mutations in genes coding for the enzyme $\gamma$-secretase and its subunits, such as nicastrin (NCSTN) and presenilin (PSENEN), in patients with familial and sporadic HS $[10,18]$, a prospective, larger-scale, population-based study with particular focus on genetic analysis would provide further insights.

\section{Conclusion}

This is one of only a few studies on HS in a population that is not predominantly Caucasian, and although this is a single-centred study, it gives some insight into the nature of HS in an Asian population. Some findings are consistent with those from the West, such as the presence of metabolic co-morbidities in both adult and paediatric HS patients. However, the male predominance noted in this and other Asian studies is contrary to studies of Western populations and may reflect genetic differences or a difference in obesity rates and/or smoking rates between genders. Further longitudinal studies may shed light on the factors influencing the development of HS.

\section{Acknowledgement}

We would like to acknowledge Prof Kang Jin-Yong for his assistance in proofreading the manuscript.

\section{Statement of Ethics}

This study was approved by the hospital research ethics committee.

\section{Disclosure Statement}

The authors have no conflicts of interest to disclose. 


\section{References}

1 Zouboulis CC, Desai N, Emtestam L, Hunger RE, Ioannides D, Juhasz I, et al: European S1 guideline for the treatment of hidradenitis suppurative/acne inversa. JEADV 2015;29: 619-644.

2 Fimmel S, Zouboulis CC: Comorbidities of hidradenitis suppurativa (acne inversa). Dermatoendocrinol 2010;2:9-16.

3 Canoui-Poitrine F, Revuz JE, Wolkenstein P, Viallette C, Gabison G, Pouget F, Poli F, Faye $\mathrm{O}$, Bastuji-Garin S: Clinical characteristics of a series of 302 French patients with hidradenitis suppurativa, with an analysis of factors associated with disease severity. J Am Acad Dermatol 2009;61:51-57.

4 Revuz JE, Canoui-Poitrine F, Wolkenstein P, Viallette C, Gabison G, Pouget F, Poli F, Faye O, Roujeau JC, Bonnelye G, Grob JJ, BastujiGarin S: Prevalence and factors associated with hidradenitis suppurativa: results from two case-control studies. J Am Acad Dermatol 2008;59:596-601.

5 Shlyankevich J, Chen AJ, Kim GE, Kimball $\mathrm{AB}$ : Hidradenitis suppurativa is a systemic disease with substantial comorbidity burden: a chart-verified case-control analysis. J Am Acad Dermatol 2014;71:1144-1150.
6 Jemec GB, Heidenheim M, Nielsen NH: The prevalence of hidradenitis suppurativa and its potential precursor lesions. J Am Acad Dermatol 1996;35:191-194.

7 Kluger N, Ranta M, Serlachius M: The burden of hidradenitis suppurativa in a cohort of patients in Southern Finland: a pilot study. Skin Appendage Disord 2017;3:20-27.

8 Scheinfeld N: Hidradenitis suppurativa: a practical review of possible medical treatments based on over 350 hidradenitis patients. Dermatol Online J 2013;19:1

9 Kurokawa I, Hayashi N; Japan Acne Research Society: Questionnaire surveillance of hidradenitis suppurativa in Japan. J Dermatol 2015; 42:747-749.

10 Xu H, Xiao X, Hui Y, Zhang X, He Y, Li C, Wang B: Phenotype of 53 Chinese individuals with nicastrin gene mutations in association with familial hidradenitis suppurativa (acne inversa). Br J Dermatol 2016;174:927-929.

11 Department of Statistics Singapore: Census of Population 2010. 2011. http://www.singstat. gov.sg/.

12 Ministry of Health Singapore: Clinical Practice Guidelines. 2016. https://www.moh.gov. sg/content/dam/moh_web/HPP/Doctors/ cpg_medical/current/2016/lipids/MOH\%20 Lipids\%20CPG\%20-\%20Booklet.pdf.
13 R Development Core Team: R: A Language and Environment for Statistical Computing. Vienna, R Foundation for Statistical Computing, 2017. http://www.R-project.org.

14 Schrader AMR, Deckers IE, van der Zee HH, Boer J, Prens EP: Hidradenitis suppurativa: a retrospective study of 846 Dutch patients to identify factors associated with disease severity. J Am Acad Dermatol 2014;71:460-467.

15 Ministry of Health Singapore: National Health Survey 2010. 2011. https://www.moh. gov.sg/content/moh_web/home/Publications/Reports/2011/national_health_survey2010.html.

16 Ogden CL, Carroll MD, Kit BK, Flegal KM: Prevalence of childhood and adult obesity in the United States, 2011-2012. JAMA 2014; 311:806-814.

17 World Health Organization: WHO Report on the Global Tobacco Epidemic 2008. http:// www.who.int/tobacco/mpower/2008/en/.

18 Pink AE, Simpson MA, Desai N, Trembath RC, Barker JNW: $\gamma$-Secretase mutations in hidradenitis suppurativa: new insights into disease pathogenesis. J Invest Dermatol 2013; 133:601-607.
Hidradenitis Suppurativa: An Asian Perspective
Skin Appendage Disord 2018;4:281-285 